\title{
Algumas notas em torno da pergunta: "o que pode a imagem?"
}

Some notes on the question: "what can images do?"

Sílvio Gallo**

Universidade Estadual de Campinas

\section{Resumo}

Este texto se propõe a pensar sobre 'o que pode uma imagem' a partir da proposição de Espinosa 'o que pode um corpo?' Estas notas foram preparadas para apresentação na mesa redonda intitulada "O que pode a imagem?", que aconteceu no Seminário Imago na UnespRio Claro em 2012. Após a apresentação, as notas foram retrabalhadas. A primeira versão do texto, com este mesmo título, foi publicada no livro Linguagens e Imagens - educação e políticas de subjetivação, organizado por Camargo; Leite e Chaluh (Ed. DP et Alii, 2014) e agora enviado para publicação na Revista Digital do LAV.

Palavras-chave: imagem, filosofia, educação

\section{Abstract}

This text proposes to think about "what an image can do" through Espinosa's proposition "what can a body do?" The present notes were prepared to presentation at the roundtable entitled "What can images do?", held as part of Imago Seminar at Unesp-Rio Claro in 2012. After the presentation, the notes were reworked. The first version of the text, with the same title, was published in the book "Linguagens e Imagens - educação e políticas de subjetivação", organized by Camargo, Leite and Chaluh (Ed. DP et Alii, 2014) and now it was submitted to publication in Revista Digital do LAV.

Keywords: image, Philosophy, Education

1. No título dessa mesa redonda do Seminário do Imago, embora seja uma pergunta (ou justamente porque é uma pergunta), está mais ou menos implícito que somos capazes de responder a ela. Se não nos julgássemos capazes de responder a essa enigmática interrogação, o mais sensato seria recusar o convite para tomar parte nesse debate. Assim, embora o título seja uma espécie de brincadeira com a célebre afirmação de Espinosa (2007, p. 167) sobre o corpo ("o fato é que ninguém determinou, até agora, o que pode o corpo..."), ele parece ser sua inversão; se o filósofo de Amsterdam afirmava a

\footnotetext{
** Professor Associado da Faculdade de Educação da Unicamp e pesquisador do CNPq. Coordenador do DiS Grupo de Estudos e Pesquisas Diferenças e Subjetividades em Educação.
}

Revista Digital do LAV - Santa Maria - vol. 9, n. 1, p. 16 - 25. - jan./abr. 2016 ISSN $1983-7348$ http://dx.doi.org/10.5902/1983734821766 
impossibilidade de definir as potencialidades do corpo, nossa tarefa aqui parece ser exatamente a de discutir as potencialidades da imagem, mesmo que não o façamos de modo exaustivo.

2. É inegável que vivemos, cada vez mais, sob o império da imagem. Nossa cultura é cada vez mais imagética. A internet é imagética. A comunicação, hoje, é imagética. Steve Jobs soube reconhecer isso muito cedo e investiu forte em sua concepção de computação e comunicação acessíveis ao grande público, de certa forma delineando o que são os gadgets que dominam hoje nosso mundo, sempre centrados em uma iconografia autoexplicativa, de modo que qualquer criança pode tomar em mãos um desses aparelhinhos e sair manipulando, com mais intimidade do que muitos adultos já com uma certa idade e não tão sensíveis e essa cultura da imagem.

2.1. Pierre Lévy foi um dos primeiros, no universo contemporâneo, a fazer dessa problemática uma questão filosófica. Seu livro de 1991 (traduzido no Brasil em 1998), $A$ ideografia dinâmica - rumo a uma imaginação artificial? procura justamente desvendar o que ele denomina uma "ideografia dinâmica" como tecnologia intelectual e explorar suas implicações para o presente e o futuro da inteligência humana e seu impacto na cultura. No prefácio do livro ele destacava:

A ideografia dinâmica apresenta um duplo caráter. Por uma lado é um projeto de engrenharia logística no âmbito das interfaces homem-máquina; por outro lado, é um ser fictício, pura hipótese, espécie de máquina a explorar o mundo dos signos e da cognição, cuja virtude talvez possa projetar novas luzes sobre antigos problemas filosóficos acerca da linguagem e do pensamento. (LÉVY, 1998, p. 13).

Lévy afirmava ainda que, no momento em que escrevia, a ideografia dinâmica era ainda um "objeto imaginário", uma utopia que talvez não viesse a se realizar, mas que era importante "sonhar com ela" de modo a pensar a reinvenção da escrita que estava em curso no final do século XX. Hoje, quase duas décadas e meia depois, qualquer pessoa com um tablet ou um smartphone nas mãos não terá dúvidas de que a ideografia dinâmica é uma realidade presente e atuante, que mudou nossas formas de comunicação, trabalho, pensamento.

Nessa afirmação de que a comunicação hoje é imagética, encontramos uma primeira possível resposta para a pergunta sobre as possibilidades da imagem: a imagem informa. Portanto, a imagem é palavra-de-ordem. Não é exatamente pensamento, mas

Revista Digital do LAV - Santa Maria - vol. 9, n. 1, p. 16 - 25. - jan./abr. 2016 ISSN 1983 - 7348 http://dx.doi.org/10.5902/1983734821766 
informação e conformação. Imagine-se numa das esquinas da Times Squareem Nova Iorque, em pleno entardecer. Você está em meio a uma profusão de imagens e cores, dos cartazes de teatro, das inúmeras propagandas e dos letreiros das lojas, além dos painéis de informações. Como trilha sonora, o ruído dos motores e das buzinas dos carros, os passos e as vozes das pessoas que falam diferentes línguas, como numa Babel pósmoderna, alguma música incidental de alguém que passa fortuitamente por você. $\mathrm{Na}$ medida em que a luz do dia diminui, as luzes dessas imagens vão ganhando cada vez mais consistência e densidade. Quando já é noite, é como se vivêssemos um outro dia, com sua luz própria. Em meio a tantas imagens, como pensar? O que pensar? Sei que se trata de um exemplo extremo; mas ele nos mostra o entorpecimento que a profusão de imagens e informações produz em nós.

Quando afirmo que a imagem informa, o faço no registro que Deleuze \& Guattari propuseram em Mil Platôs, quando dizem que a "a linguagem seria informativa e comunicativa" (1980, p. 95). ${ }^{1}$ Segundo os autores, a função da linguagem é política: "a linguagem não é feita mesmo para que se acredite nela, mas para obedecer e fazer obedecer" (1980, p. 96), daí a afirmação de que ela é palavra-de-ordem. Seguem eles:

As palavras não são ferramentas; mas damos para as crianças linguagem, canetas e cadernos, assim como damos pás e picaretas para os operários. Uma regra de gramática é um marcador de poder, antes de ser um marcador de sintaxe. A ordem não se relaciona com significações prévias, nem com uma organização prévia de unidades distintivas, mas o inverso. A informação não é mais que o mínimo estritamente necessário para a emissão, transmissão e observação das ordens enquanto comandos. (DELEUZE; GUATTARI, 1980, p. 96).

Ora, se a imagem é uma linguagem, se falamos hoje em uma linguagem imagética, se assumimos a noção de ideografia dinâmica tal como pensada por Lévy, essa afirmação da imagem como palavra-de-ordem ganha consistência. Quando se clica com o dedo sobre um ícone na tela de seu tablet, se está transmitindo um comando; quando se vê uma imagem, se recebe um comando, espera-se por uma ação. As ações realizadas como resultados de comandos, palavras-de-ordem são, via de regra, realizadas de modo irrefletido. Ninguém pensa para obedecer uma ordem; se pensar, não obedece...

2.2. Donde deriva uma nova pergunta: a imagem pode algo como pensamento? Ou, dizendo de outro modo: pode a imagem devir pensamento?

\footnotetext{
${ }^{1}$ Na edição brasileira de Mil Platôs o texto a que me refiro, 20 de novembro de 1923 - Postulados da Linguística, está publicado no volume 2.
}

Revista Digital do LAV - Santa Maria - vol. 9, n. 1, p. 16 - 25. - jan./abr. 2016 ISSN 1983 - 7348 http://dx.doi.org/10.5902/1983734821766 
3. Imagem-Informação-Representação.

A imagem é informação, palavra-de-ordem porque, pelo menos desde Platão, é tomada como representação. No Dicionário Houaiss, encontramos como sua definição e derivações:

1. representação da forma ou do aspecto de ser ou objeto por meios artísticos $<$ i. desenhada, gravada, pintada, esculpida >

1.1. representação de seres que são objeto de culto, de veneração

〈 a i. de Cristo > u uma i. de são Francisco >

1.2. estampa, sem caráter de obra original ou rara, que reproduz temas diversos

ou, mais esp., motivos religiosos

< um álbum de i. > < algumas i. marcavam as páginas do missal >

2. aspecto particular pelo qual um ser ou um objeto é percebido; cena, quadro $\langle$ imagens da rua > $i$. urbanas >

3. reprodução invertida de um ser ou de um objeto, transmitida por uma superfície refletora

4. reprodução estática ou dinâmica de seres, objetos, cenas etc. obtida por meios técnicos

$\langle i$. fotográfica $\rangle\langle i$. televisada $\rangle\langle i$. magnética $\rangle$

5. fig. pessoa muito bonita; cromo

6. fig. aquilo que apresenta uma relação de analogia, de semelhança (simbólica

ou real); réplica, retrato, reflexo

< ela é a $i$. do pai > < a casa era a i. da dona >

7. fig. pessoa que representa, simboliza ou faz lembrar alguma coisa abstrata; personificação

< ela era a própria $i$. da tristeza e solidão > < o rapaz é a $i$. da saúde >

8. fig. opinião (contra ou a favor) que o público pode ter de uma instituição, organização, personalidade de renome, marca, produto etc.; conceito que uma pessoa goza junto a outrem

< um político precisa cuidar de sua $i$. > < teve a i. abalada pelo escândalo >

9. lit qualquer maneira particular de expressão literária que tem por efeito substituir a representação precisa de um fato, situação etc. por uma alegoria, visão, evocação etc.

$\langle i$. bíblicas $\rangle\langle i$. camonianas $\rangle\langle i$. vulgares $\rangle$

10. mat elemento determinado pela aplicação de uma função em um determinado ponto

11. ópt representação de um objeto que emite ou recebe luz e que é formada por raios luminosos que passam por uma lente, espelho ou qualquer outro sistema óptico

12. psic representação ou reprodução mental de uma percepção ou sensação anteriormente experimentada

$<$ i. visual, olfativa >

13. psic representação mental de um ser imaginário, um princípio ou uma abstração

< a i. do demônio, da realeza, da democracia, do círculo > (Grande Dicionário Houaiss da Língua Portuguesa:

http://houaiss.uol.com.br/busca?palavra=imagem). 
Nesse conjunto de acepções do termo imagem dicionarizado, fica evidente seu sentido comum como representação de algo, repetição, abstração. Se buscarmos, na mesma fonte, sua etimologia, encontramos que ela deriva do latim, imago, que significa: semelhança, representação, retrato.

Vemos, pois, que cristalizou-se no ocidente a noção de imagem como representação, como reprodução, como repetição. No primado da representação, a imagem informa, conforma, induz o não-pensamento. Como foi dito antes, transmite palavras-de-ordem, induzindo a uma ação, exigindo obediência.

3.1. Em Diferença e Repetição Gilles Deleuze procurou fazer a crítica do pensamento como representação, na direção de investir num pensamento como criação, não como cópia, repetição, reprodução. Ainda que não seja nosso interesse central aqui, vale ressaltar que para ele a filosofia hegemônica no ocidente é essa filosofia em que o pensamento é tomado como representação, uma filosofia centrada no conceito de identidade, incapaz de conceber a diferença senão em relação com o idêntico. Na busca de construção de uma filosofia da diferença, na qual ela seja pensada e afirmada por si mesma, Deleuze insistiu no pensamento como criação.

Nesse contexto, afirmou que pensamos sempre no contexto de uma "imagem do pensamento", que define os contornos e as possibilidades do que seja pensar. A imagem do pensamento é o pressuposto implícito e pré-filosófico de toda filosofia:

... o pensamento conceitual filosófico tem como pressuposto implícito uma Imagem do pensamento, pré-filosófica e natural, tirada do elemento puro do senso comum /.../ E é sobre esta imagem que cada um sabe, que se presuma que cada um saiba o que significa pensar. (DELEUZE, 2006, p. 192).

Ora, se pensamos no contexto de uma imagem do pensamento que define o que é possível e o que não é possível pensar, essa imagem é justamente aquilo que impede que o pensamento aconteça, escape desses contornos e crie o novo. Pensar no contexto de uma imagem do pensamento é repetir o já pensado, não é pensar o novo, o diferente. Para pensar o novo, o diferente, Deleuze afirma ser necessário investir na produção de um "pensamento sem imagem", um pensamento virgem, "genital", sem contornos prédefinidos.

Um pensamento sem imagem seria um pensamento que escapasse à imagem palavra-de-ordem que determina o que é pensar, experimentando possibilidades 
insuspeitadas. Um pensamento que escapasse à tirania da representação e exercitasse a criação.

Então, se a imagem é representação e palavra-de-ordem, se ela induz ao não pensamento ao definir o que seja o pensar através de uma imagem do pensamento, impõese, pois, mais uma questão: como arrancar a imagem do primado da representação? Seria possível pensar a imagem não como representação, mas com algum outro estatuto ontológico? Se for possível, quais seriam as consequências dessa nova concepção de imagem?

4. Virtualidades de uma imagem-pensamento

Encontramos no próprio Deleuze uma possibilidade de resposta para a interrogação levantada anteriormente: é uma imagem-sensação que pode devir uma imagempensamento.

É curioso o percurso que podemos ver na obra desse filósofo, quando se trata da questão da imagem. Na década de 1960, em Diferença e Repetição, encontramos uma perspectiva crítica da imagem como representação, sendo que a única possibilidade para escapar a uma "imagem do pensamento" seria a produção de um "pensamento sem imagem", como que atestando ser impossível pensar a imagem fora do contexto da representação. Porém, em três obras da década de 1980 isso muda radicalmente e a imagem aparece em perspectivas não representacionais e como possibilidade criativa para o pensamento. O primeiro livro foi dedicado à pintura de Bacon: Francis Bacon - Lógica da Sensação (1981); os outros dois foram dedicados ao cinema: Cinema 1 - A imagemmovimento (1983) e Cinema 2 - A imagem-tempo (1985).

No livro sobre Bacon, Deleuze argumenta que o pintor trabalha com uma imagem que não é representacional, figurativa, uma vez que ele pinta a sensação. Ao pintar a sensação, Bacon não representa algo com suas imagens; elas simplesmente exprimem o que é sentido. Não foi Bacon, porém, que inaugurou essa via, mas ela remonta a Cézanne, que a nomeou, e a outros antes dele.

Há duas maneiras de ultrapassar a figuração (quer dizer, tanto o ilustrativo quanto o narrativo): em direção à forma abstrata, ou em direção à Figura. Cézanne deu a essa via da figura um nome simples: a sensação. A Figura é a forma sensível referida à sensação; ela age imediatamente sobre o sistema nervoso, que é carne, enquanto a Forma abstrata se dirige ao cérebro e age por intermédio do cérebro, mais próximo do osso. Cézanne certamente não inventou essa via da sensação na pintura, mas deu-lhe um

Revista Digital do LAV - Santa Maria - vol. 9, n. 1, p. 16 - 25. - jan./abr. 2016 ISSN 1983 - 7348 http://dx.doi.org/10.5902/1983734821766 
estatuto sem precedentes. A sensação é o contrário do fácil e do lugar-comum, do clichê, mas também do "sensacional", do espontâneo etc. /.../ A lição de Cézanne vai além dos impressionistas: não é no jogo "livre" ou desencarnado da luz e da cor (impressões) que está a Sensação, mas no corpo, mesmo que no corpo de uma maçã. A cor está no corpo, a sensação está no corpo, e não no ar. A sensação é o que é pintado. O que está pintado no quadro é o corpo, não enquanto representado como objeto, mas enquanto vivido como experimentando determinada sensação (o que Lawrence, falando de Cézanne, chamava de "o ser maçãnesco da maçã").

Eis o fio que liga Bacon a Cézanne: pintar a sensação, ou, como diz Bacon, usando palavras muito próximas das de Cézanne, registrar o fato. (Deleuze, 2007, p. 42-43, os grifos no primeiro parágrafo citado são meus; os últimos são do próprio autor).

Pintar a sensação é muito diferente de representar um objeto; a imagem pintada já não é a representação de um corpo, ela é o corpo mesmo, enquanto sensação. As sensações do pintor são transformadas em obra, uma nova sensação, que por sua vez provoca sensações naqueles que a observam. Em um obra posterior, O que é a filosofia?, Deleuze \& Guattari caracterizam a obra de arte como um "bloco de sensações": a partir de suas percepções e afeç̧ões, o artista cria perceptos e afectos, encerrando-os em um bloco de sensações (um quadro, uma música, um filme, um poema etc.) que por sua vez provocará novas percepções e afecções (diferentes daquela do artista) naqueles que entrarem em contato com a obra. Por isso, para Deleuze, a obra de arte não comunica; ela expressa sensações, ela provoca sensações. Entre as sensações expressadas e aquelas provocadas há um hiato, às vezes mesmo um abismo. A arte consiste num jogo de sensações, não em comunicar palavras-de-ordem.

De modo que, nesta perspectiva, a imagem, enquanto imagem-sensação, já não está no registro da representação e apresenta seu potencial próprio de produção de sensações e capacidade de incitar o pensamento, de fazer pensar. Esse tipo de imagem vai além da figuração, da ilustração; ele não apenas repete um objeto, ela é ela mesma um novo objeto, mas um objeto de sensações. Uma perspectiva análoga move o pensamento de Deleuze quando explora as potencialidades do cinema, especialmente ao falar de uma imagem-tempo.

Fora da representação, da ilustração, da figuração, a imagem-sensação já não é comunicação nem palavra-de-ordem. Imagens-sensação na pintura, na fotografia, no cinema, que não são produzidas para transmitir uma informação ou fornecer um comando, mas para encerrar um bloco de sensações com potencial de produzir novas sensações, afetando o pensamento e provocando sua emergência. É nesse sentido que a imagemsensação pode devir imagem-pensamento. Não uma imagem do pensamento, no contexto

Revista Digital do LAV - Santa Maria - vol. 9, n. 1, p. 16 - 25. - jan./abr. $2016 \quad$ ISSN 1983 - 7348 http://dx.doi.org/10.5902/1983734821766 
da representação, mas uma imagem-pensamento, um pensamento imagético que delira e cria.

5. Imagem-sensação no cinema e potência do pensamento

Para finalizar essas notas que rodeiam a pergunta sobre o que pode a imagem, recorro a dois ensaios de pensar a imagem-sensação em dois filmes de Pedro Almodóvar.

5.1. Kika é uma comédia dramática de 1993, muito representativa da produção de Almodóvar na década de 1990. Na estética kitsch ${ }^{2}$ de Almodóvar a profusão e o forte contraste de cores encarnam a imagem-sensação. O enredo permeado de non-sense é pura produção de sentido e de sensações. É impossível assistir ao filme sem ser afetado por ele, sejam quais forem as afecções que ele produza no expectador.

O que destaco nesse ensaio de pensar uma imagem-sensação nesse filme é uma cena protagonizada por uma personagem secundária, Andrea Caracortada (seu rosto é atravessado por uma cicatriz). Andrea é uma psicóloga que se tornou repórter e apresentadora de um programa de TV que explora as notícias sensacionalistas do "mundo cão", especialmente aquelas envolvendo crimes e assassinatos. Ela se veste de modo extravagante e, para gravar suas cenas externas, veste uma roupa de couro colada ao corpo, com um capacete no qual há uma câmera de TV, de modo que aquilo que ela filma é aquilo que ela vê (e lembremos que falamos de um tempo em que a miniaturização ainda não havia chegado tão fortemente aos equipamentos eletrônicos...).

Cenas com Andrea Caracortada atravessam o filme; partes de seu programa de TV, insinuações sobre relacionamentos seus com certos personagens. Em uma das cenas da última parte do filme Andrea força uma entrevista com um dos personagens centrais, um escritor que ela julga ser um serial killer, que escreve seus romances a partir dos assassinatos que comete. Ela está tentando extrair uma confissão, enquanto grava tudo.

No confronto e discussão entre ambos, ela o acerta com um tiro, de modo acidental. Mas segue tentando fazer com que ele, à beira da morte, confesse seus crimes para a câmera. Ele não confessa nada, mas consegue também atirar em Andrea. Os dois morrem, um nos braços do outro, com o sangue se esvaindo de seus corpos. O "banho de sangue" dessa cena produz um conjunto de imagens-sensação, que estão completamente além de qualquer representação, mas provocam o pensamento.

Almodóvar não está comunicando nada; não há ali qualquer "lição de moral", não há palavras-de-ordem. Há sensação pura. Sensação de cada um dos personagens;

\footnotetext{
${ }^{2}$ A esse respeito, bem como para um comentário geral sobre o cinema de Almodóvar, ver: POLIMENI, 2004.
}

Revista Digital do LAV - Santa Maria - vol. 9, n. 1, p. 16 - 25. - jan./abr. 2016 ISSN 1983-7348 http://dx.doi.org/10.5902/1983734821766 
Algumas notas em torno da pergunta: "o que pode a imagem?"

sensação do diretor, sensação do expectador que assiste ao filme preso na tela. Miríade de sensações em uma profusão de cores, sons e passeios de câmera. Como ficar apático frente a isso?

5.2. Abraços Partidos (Los Abrazos Rotos) é um drama de 2009, já de uma outra fase criativa de Almodóvar. Aqui trata-se de um cineasta, Mateo Blanco, que, num acidente de carro, perde sua amante e fica cego. Já não podendo fazer filmes, ele assume uma outra identidade, passando a chamar-se Harry Caine, e passa a escrever roteiros, afirmando que Blanco morreu no acidente, junto com sua amada. Mas, quando quatorze anos depois reencontra os rolos do filme que acabara de filmar antes do acidente, decide finalizar sua montagem. A perspectiva de um cineasta cego que decide ainda assim terminar a montagem de seu filme já é por demais sugestiva.

Mas destaco uma cena em especial, na qual Mateo Blanco está com seu filho adolescente vendo um vídeo do acidente de carro que sofreu (o acidente fora filmado por alguém que os perseguia). Na tela, o último beijo que trocaram, instantes antes do carro ser atingido por outro, causando a morte da amada, sua cegueira e uma perda de memória. O rapaz narra para Mateo as cenas. Ele pede para pausar o vídeo na cena do beijo, aproxima-se da tela e começa a tateá-la com as mãos. A cena vai seguindo lentamente, quadro a quadro, Mateo acariciando o rosto da amada na tela que não pode ver. Aos poucos suas mãos emolduram aquele rosto, até que ele desaparece no final da cena.

A imagem-sensação aqui é forte; como capturar a imagem na cegueira? Como sentir o não visto? Como pensar o que foi visto, mas esquecido? Que tipo de sensação é essa evocada por uma imagem, se a única coisa que o protagonista sente é o frio liso de uma tela de TV em seus dedos? E, no entanto, ele sabe que o rosto da amada está lá, depois do último beijo que trocaram. A imagem não representa nada; ela é sensação pura, puro sentido produzido na relação. $E$, na afecção que produz no sujeito, incita o pensamento.

A imagem-sensação aproxima-nos daquilo que Julio Cabrera (2006) definiu como uma "logopatia" que é produzida pelo cinema, isso é, uma mistura de afecção, sentimento (pathos) e pensamento (logos). O cinema nos mobiliza, nos afeta, não nos deixa apáticos; gostamos de um filme ou não gostamos dele, mas não podemos simplesmente vê-lo e ignorá-lo. E nessa afecção, mobilizam-se as potências do pensamento.

O que vale para o cinema enquanto logopatia, penso, pode ser também aplicado, com adaptações, para a fotografia, as artes plásticas, outros tipos de imagem, estáticas ou em movimento.

Revista Digital do LAV - Santa Maria - vol. 9, n. 1, p. 16 - 25. - jan./abr. 2016 ISSN 1983 - 7348 http://dx.doi.org/10.5902/1983734821766 
6. Finalizo essas notas esparsas, sem nenhuma intenção de concluir, de fechar questão. Quis apenas levantar algumas possibilidades de exploração em torno da pergunta que motivou a mesa redonda para a qual esse texto foi produzido: as possibilidades da imagem. E transitamos de uma imagem-comunicação, que se produz como palavra-de-ordem, que induz a uma ação e ao não pensamento para uma imagem-sensação que, num jogo logopático, nada representa, mas cria um universo de sensações que mobilizam o pensamento.

Não é pouco, o que pode a imagem...

\section{Referências}

CABRERA, Julio. O cinema pensa. Rio de Janeiro: Rocco, 2006.

DELEUZE, Gilles. Cinéma 1 - L'image-mouvement. Paris: Minuit, 2010.

DELEUZE, Gilles. Cinéma 1 - L'image-temps. Paris: Minuit, 2009.

DELEUZE, Gilles. Diferença e Repetição. 2a ed. Rio de Janeiro: Graal, 2006.

DELEUZE, Gilles. Francis Bacon - lógica da sensação. Rio de Janeiro: Jorge Zahar, 2007.

DELEUZE, Gilles; GuATTARI, Félix. Mille Plateaux. Paris: Minuit, 1980.

DELEUZE, Gilles; GUATTARI, Félix. 20 de novembro de 1923 - Postulados da Linguística. In: Mil Platôs - vol. 2. Rio de Janeiro: Ed. 34, 1995, p. 11-59.

DELEUZE, Gilles; GUATTARI, Félix. O que é a filosofia?. Rio de Janeiro: Ed. 34, 1992.

LÉVY, Pierre. A ideografia dinâmica - rumo a uma nova imaginação artificial? São Paulo: Loyola, 1998.

POLIMENI, Carlos. Pedro Almodóvar y el kitsch español. Madrid: Campo de Ideas, 2004.

SPINOZA. Ética. Belo Horizonte: Autêntica, 2007.

\section{Referências filmográficas}

Kika. Direção de Pedro Almodóvar. Espanha/França, 1993, 114 min. (DVD Spectra Nova). Abraços Partidos (Los abrazos rotos). Direção de Pedro Almodóvar. Espanha, 2009, 127 min. (DVD Universal Pictures). 